\section{Inmunohistoquímica en un caso de encefalitis por virus de Epstein Barr}

\author{
Edenilson E. Calore, Nilda M. Pérez, \\ José F. Martins y Paola G. Cárdenas
}

\section{Imunohistochemistry in a case of EBV encephalitis}

EBV can produce a broad range of CNS disorders such as demyelinative diseases, acute encephalitis, cerebellar ataxia, myelitis, or meningitis. The role of EBV itself in acute encephalitis is not completely clear. Presently we described a 4 years old boy with EBV encephalitis that deceased after respiratory distress and cardio-respiratory arrest. At autopsy the most important changes in the brain were focal sub cortical peri-vascular mononuclear inflammation of the cerebral vessels. EBV antigens were demonstrated by immunohistochemistry in some cells of the vascular walls and in some glial cells of the brain. As expected this indicates a predominantly cellular response in the brain. The presence of EBV antigens by immunohistochemistry associated to a scarce inflammatory infiltrate supports the hypothesis that EBV itself plays a major role in the pathogenesis of EBV encephalitis.

Key words: Infectious mononucleosis, Epstein Barr virus, encephalitis, immunohistochemistry, EBV, vasculitis.

Palabras clave: Mononucleosis infecciosa, virus de Epstein-Barr, encefalitis, inmunohistoquímica, EBV, vasculitis.

\section{Introducción}

$\mathrm{L}$

a mononucleosis infecciosa es causada por el virus de Epstein Barr

(VEB) y se caracteriza por fiebre, exantema, inflamación tonsilar

y de ganglios linfáticos, linfocitos atípicos en sangre periférica y disfunción hepática ${ }^{1}$. En forma ocasional, el VEB puede tener manifestaciones en el sistema nervioso central (SNC) como encefalitis aguda, ataxia cerebelosa aguda, mielitis o meningitis ${ }^{2-5}$. Los estudios epidemiológicos indican que la encefalitis es una complicación poco frecuente de la infección por VEB, que se produce en 0,05 casos por año en una población de un millón de habitantes ${ }^{6}$. Se han descrito casos de encefalitis por VEB en pacientes inmunocomprometidos, especialmente con $\operatorname{SIDA}^{7}$ y en receptores de trasplantes de células madre hematopoyéticas ${ }^{8,9}$.

La patogénesis de la encefalitis aguda por VEB no está del todo aclarada. Se postula que las lesiones cerebrales pueden ser causadas en forma directa por el virus o por factores inflamatorios séricos, como citoquinas. Se describe la autopsia de un caso de encefalitis fatal con hallazgos de antígenos de VEB por inmunohistoquímica.

\section{Caso anátomo-clínico}

Niño de sexo masculino, de 4 años de edad que presentó un cuadro caracterizado por exantema, fiebre no cuantificada y tos. Se diagnosticó una infección respiratoria alta por lo que recibió amoxicilina/ácido clavulánico.

\footnotetext{
Instituto de Infectología Emilio Ribas, Sao Paulo, Brasil.

Departamento de Patología.

Recibido:3 de febrero de 2012 / Aceptado: 31 de agosto de 2012

Correspondencia a:

Edenilson E. Calore

eecalore@hotmail.co
}

Veinte días después del inicio del cuadro, presentó deterioro clínico con dificultad respiratoria rápidamente progresiva. Fue internado con una $\mathrm{T}^{\circ} \mathrm{de}$ $37,5^{\circ} \mathrm{C}$, perfusión periférica regular, presión arterial normal, FC: 115 latidos por min, FR: 28 por min, auscultación pulmonar y cardíaca normales. Del punto de vista neurológico, el paciente estaba consciente y con agitación psicomotora. Recibió terapia con oxígeno y se instaló acceso venoso periférico. A las pocas horas del ingreso presentó un paro cardio-respiratorio. Se le realizó reanimación cardiopulmonar, intubación traqueal, conexión a ventilación mecánica y fue trasladado a una unidad de cuidado intensivo. La tomografía axial encefálica mostró un edema cerebral difuso. Dentro de las pruebas de laboratorio sólo destacaba una leucocitosis leve. Las pruebas serológicas, IgM e IgG anti-cápside por método de ELISA, así como la RPC in-house para VEB, realizada en suero, fueron positivas. Las pruebas serológicas para herpes simplex y CMV fueron negativas. Evolucionó grave falleciendo a los 10 días desde su ingreso.

En la autopsia se tomaron muestras de pulmones, corazón, hígado, bazo, páncreas, riñón y médula ósea. El cerebro fue fijado en formol durante 10 días. Se tomaron muestras de corteza cerebral, regiones subcorticales, cuerpo calloso, putamen, cerebelo, tronco cerebral y médula espinal cervical, siendo sometidas a técnicas histológicas y diversas tinciones (hematoxilina-eosina, Veighert para fibras elásticas y Weill para mielina). Las reacciones de inmunohistoquímica para VEB (Dako®-monoclonal de ratón, anti-proteína latente de membrana (LMP1), herpes simplex 1 y 2 (Dako®-policlonal de conejo), CMV (Novocastra ${ }^{\circledR}-$ monoclonal de ratón), así como anti-CD20 (Dako $\left.{ }^{\circledR}\right)$, CD3 (Chemicon $\left.{ }^{\circledR}\right)$, CD4 (Novocastra $\left.{ }^{\circledR}\right)$, CD8 (Chemicon $\left.{ }^{\circledR}\right)$ y CD68 (Dako $\left.{ }^{\circledR}\right)$, todos monoclonales de ratón, se realizaron en fragmentos seleccionados de cerebro, pulmones, hígado y bazo. Para la recuperación de antígenos, las secciones fueron tratadas previamente por calentamiento en $10 \mathrm{mM}$ citrato buffer, $\mathrm{pH}$ 6,0; por $20 \mathrm{~min}$. Después del enfriamiento, las secciones se sumergieron en PBS que contenía $3 \%$ de peróxido de hidrógeno durante $10 \mathrm{~min}$. Las secciones fueron incubadas en una cámara húmeda durante una noche a $4^{\circ} \mathrm{C}$ con un anticuerpo primario. Las láminas fueron elaboradas con diaminobencidina- $\mathrm{H}_{2} \mathrm{O}_{2}$, contrastadas con hematoxilina. Se realizaron controles negativos.

En la autopsia, el examen macroscópico mostró consolidaciones pulmonares focales y edema cerebral. El examen histológico demostró una bronconeumonía focal, hipertrofia moderada de los folículos linfoides peri-bronquiales y destrucción del epitelio bronquial. Se observaron focos con inflamación mononuclear en el intersticio renal y en los espacios porta del hígado. En el cerebro se evidenciaron cambios isquémicos de algunas neuronas corticales en la corteza parietal (secundaria a la hipoxia), hemorragia sub-cortical focal peri-vascular y escasa inflamación mononuclear peri-vascular de los vasos cerebrales.

Los antígenos del VEB se demostraron mediante técnicas de inmunohistoquímica en algunas células de las paredes vasculares, en particular en las células endoteliales (Figura 1) y en células gliales del cerebro (Figura 2). Las células inflamatorias fueron predominantemente CD68 positivas y escasas CD8 positivas. No había signos de desmielinización. Los antígenos del VEB se observaron en las células mononucleares de los folículos peribronquiales, pero no en los demás órganos. Las células CD8 mostraron un claro predominio en los espacios porta y en los folículos peri-bronquiales. Se observaron escasas células CD4 en los espacios porta y células CD20 en el centro germinal de los folículos linfoides peri-bronquiales.

\section{Discusión}

La patogénesis de las lesiones del SNC asociadas al VEB no se conoce completamente. Algunos autores sugieren directamente la infección por el 


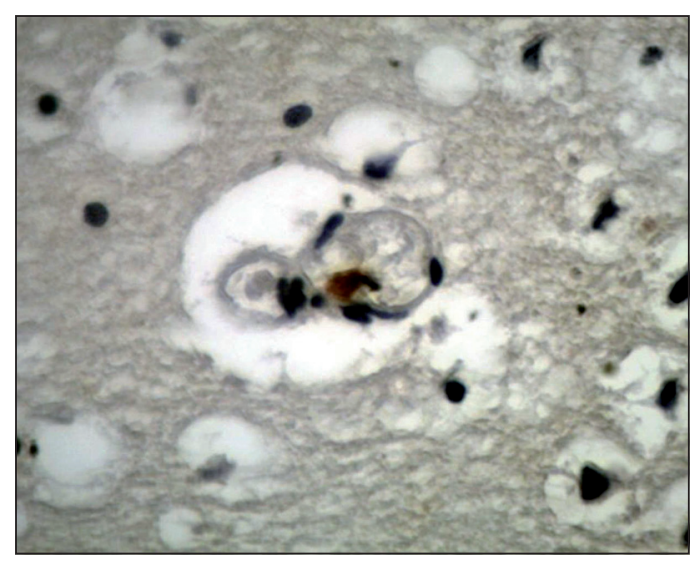

Figura 1. Inmunohistoquímica positiva para antígeno de VEB en una de las células endoteliales en tejido cerebral.

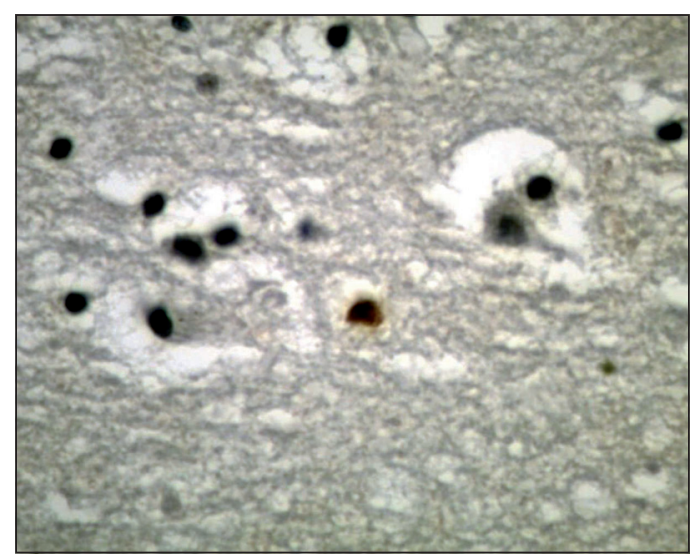

Figura 2. Inmunohistoquímica positiva para antígeno de VEB en células de la glía (células de color marrón) (aumento $1 \times 400)$
VEB como causa de los síntomas neurológicos basados en la presencia del genoma del virus, por RPC en el LCR de casos de meningoencefalitis ${ }^{10,11}$. Las secuencias genómicas del VEB también se han observado en el LCR por RPC en encefalomielitis diseminada aguda (EMDA) asociados con infección por el $\mathrm{VEB}^{5}$. Sin embargo, algunos de los síntomas neurológicos se han asociado a mecanismos inmunológicos. En un caso de infección por VEB se demostró la presencia de anticuerpos séricos anti-neurales, lo que explicaría la desmielinización ${ }^{12}$. Los estudios histológicos del SNC en la encefalitis por VEB han contribuido para comprender su patogénesis. Los principales patrones histopatológicos de la encefalitis asociado al VEB son: EMDA, encefalitis con infiltrados mononucleares peri-vasculares y encefalitis hemorrágica edematosa ${ }^{13-15}$.

En el presente caso la hemorragia focal sub-cortical se observó en algunas áreas del cerebro, generalmente junto a los pequeños vasos sanguíneos. Las células inflamatorias eran escasas, sobre todo CD68 positivas (macrófagos) y con menor frecuencia células CD8 positivas. Esto indica una respuesta predominantemente celular en el cerebro. La presencia de antígenos del VEB mediante técnicas de inmunohistoquímica, asociada a un escaso infiltrado inflamatorio apoya la hipótesis de que el virus en sí puede jugar un rol importante en la patogénesis de la encefalitis por VEB, aunque no se puede excluir que factores como las citoquinas séricas también serían responsables de las lesiones cerebrales y algunos de los síntomas neurológicos. La presencia de antígenos del VEB en células endoteliales podría explicar algunos cambios patológicos observados en la encefalitis clásica por EBV, como fragilidad vascular y hemorragia, observadas en este caso. Por último, en este paciente no se realizó estudio inmunológico por lo que no puede descartarse una inmunodeficiencia que pudo haber contribuido al desenlace fatal.

\section{Referencias bibliográficas}

1.- Evans AS. Infectious mononucleosis and other mono-like syndromes. N Engl J Med 1972; 286: 836-8.

2.- Bhatti N, Larson E, Hickey M, Seal D. Encephalitis due to Epstein-Barr virus. J Infect 1990; 20: 69-72.

3.- Cleary TG, Henle W, Pickering LK. Acute cerebellar ataxia associated with Epstein-Barr virus infection. JAMA 1980; 243: 148-9.

4.- Caldas C, Bernicker E, Nogare A D, Luby J P. Case report: transverse myelitis associated with Epstein-Barr virus infection. Am J Med Sci 1994; 307: 45-8.
5.- Fujimoto H, Asaoka K, Imaizumi T, Ayabe M, Shoji H, Kaji M. Epstein-Barr virus infections of the central nervous system. Intern Med 2003; 42: 33-40.

6.- Kamei S, Takasu T. Nationwide survey of the annual prevalence of viral and other neurological infections in Japanese inpatients. Intern Med 2000; 39: 894-900.

7.- Polilli E, Sozio F, Mazzotta E, Consorte A, Di Masi F, Agostinone A, et al. Rapidly progressive and fatal EBV-related encephalitis in a patient with advanced HIV-1 infection at presentation: a case report and review of the literature. New Microbiol 2010; 33: 275-80.

8.- Schmidt-Hieber M, Schwender J, Heinz WJ, Zabelina T, Kühl JS, Mousset S, et al. Viral encephalitis after allogeneic stem cell transplantation: a rare complication with distinct characteristics of different causative agents. Haematologica 2011; 96: 142-9.

9.- Jaskula E, Dlubek D, Sedzimirska M, Duda D, Tarnowska A, Lange A. Reactivations of cytomegalovirus, human herpes virus 6, and EpsteinBarr virus differ with respect to risk factors and clinical outcome after hematopoietic stem cell transplantation. Transplant Proc 2010; 42: 3273-6.

10.- Imai S, Usui N, Sugiura M, Osato T, Sato T, Tsutsumi H, et al. EpsteinBarr virus genomic sequences and specific antibodies in cerebrospinal fluid in children with neurologic complications of acute and reactivated EBV infections. J Med Virol 1993; 40: 278-84.

11.- Landgren M, Kyllerman M, Bergstrom T, Dotevall L, Ljungström L, Ricksten A. Diagnosis of Epstein-Barr virus-induced central nervous system infections by DNA amplification from cerebrospinal fluid. Ann Neurol 1994; 35: 631-5.

12.- Ito H, Sayama S, Irie S, Kanazawa N, Saito T, Kowa H, et al. Antineuronal antibodies in acute cerebellar ataxia following Epstein-Barr virus infection. Neurology 1994; 44: 1506-7.

13.- Häusler M, Ramaekers V T, Doenges M, Schweizer K, Ritter K, Schaade L. Neurological complications of acute and persistent Epstein-Barr virus infection in paediatric patients. J Med Virol 2002; 68: 253-63.

14.- Francisci D, Sensini A, Fratini D, Moretti MV, Luchetta ML, Di Caro A, et al. Acute fatal necrotizing hemorrhagic encephalitis caused by EpsteinBarr virus in a young adult immunocompetent man. J Neurovirol 2004; 10: 414-7.

15.- Takeuchi S, Takasato Y, Masaoka H, Hayakawa T, Otani N, Yoshino Y, et al. Hemorrhagic encephalitis associated with Epstein-Barr virus infection. J Clin Neurosci 2010; 17: 153-4. 